\title{
A retrospective analysis of emergency room visits of oral and maxillofacial surgery patients in a tertiary care hospital
}

\author{
Si-Yeon Park, Jae-Min Song*, Jun-Ho Lee, Jae-Yeol Lee, Dae-Seok Hwang, Yong-Deok Kim, Sang-Hun Shin, Uk-Kyu Kim
}

Department of Oral and Maxillofacial Surgery, School of Dentistry, Pusan National University, Yangsan, Korea

\begin{abstract}
To investigate the present trends in the causes of patients visiting the emergency room of tertiary care hospital and were treated at the Department of Oral and Maxillofacial Surgery in order to prepare emergency room treatment guidelines. Increasing numbers of patients with damage to the oral and maxillofacial area visit the emergency room for treatment. This retrospective study analyzed 5,104 patients who had visited the emergency room of Pusan National University Yangsan Hospital and treated at the Department of Oral and Maxillofacial Surgery, between August 2012 and July 2017. The patients were divided into groups according to their injury types, such as trauma, infection, bleeding, temporomandibular joint disorders, and others. The number and frequency of patients in each type of injury group were analyzed as percentages (\%) using SPSS 23.0 software. The male to female ratio of the patients visiting the emergency room was 1.98:1, with most patients aged below 10 years old. The majority of patients were in the trauma, infection, and bleeding groups. Fractures, especially mandibular fractures, were frequently present in the trauma group. In the oral and maxillofacial area, the results of the frequency, age, and type of injury treated in the emergency room from this study were not significantly different from those of other studies in the past. However, the reasons for the visit are still diverse and complex.
\end{abstract}

Key Words: Emergencies, Oral surgery, Tertiary care centers

(c) This is an open-access article distributed under the terms of the Creative Commons Attribution Non-Commercial License (http://creativecommons.org/licenses/by-nc/4.0) which permits unrestricted noncommercial use, distribution, and reproduction in any medium, provided the original work is properly cited.

\section{INTRODUCTION}

With the rapid advances in modern civilization and increasing reach of the media, medical knowledge is increasingly generalized. There has been a notable increase in the number of medical institutions, significant improvement in medical standards, and access to treatment, while the reasons for hospital visits have diversified [1,2]. In the oral and maxillofacial region, such reasons may range from a simple toothache to life-threatening multiple fractures or dental infections. The range of complications is very wide relative to the anatomical area. The frequency of damage in this region is also high, due to its exposure to the external environment [3,4].

Although there has been an increase in the number of patients visiting the emergency room due to oral or maxillofacial conditions, the number of emergency medical facilities and the size of the medical staff providing rapid

Received March 4, 2019; Revised March 17, 2019; Accepted March 18, 2019

Corresponding author: Jae-Min Song, Department of Oral and Maxillofacial Surgery, School of Dentistry, Pusan National University, 49 Busandaehak-ro, Mulgeum-eup, Yangsan 50612, Korea.

Tel: +82-51-240-7429, Fax: +82-51-240-7706, E-mail: songjm@pusan.ac.kr

Copyright $\odot$ 2019, Oral Biology Research Institute 
and accurate treatment is small. The primary treatment provided during emergency care has a marked influence on patient prognosis; however, emergency treatment of the oral and maxillofacial areas is still not satisfactorily standardized [5].

In order to ensure correct primary treatment, a basic understanding of emergency medical conditions in the oral and maxillofacial regions is necessary [5-11]. Therefore, our department performs a study of emergency patients every 5 years, to establish trends that can be used to adapt treatment strategies [11]. The present study sought to compare the results of previous studies, in order to establish emergency room trends in the oral and maxillofacial field, with a view to improving the functioning of the emergency room to reflect the trends and injury types of patients and to be prepared to offer the appropriate treatment.

\section{MATERIALS AND METHODS}

\section{Patients}

This was a retrospective study conducted on 5,104 patients who visited the emergency room of Pusan National University Yangsan Hospital and who were then treated in the Department of Oral and Maxillofacial Surgery (OMS), between August 2012 to July 2017. This study was reviewed by the institutional review board of Pusan National University Dental Hospital and was approved from deliberation (IRB no. PNUDH-2018-027).

\section{Statistical analysis}

Based on the patient's medical records, radiographs, and clinical pictures, the patients were divided into trauma, infection, bleeding, temporomandibular joint disorders (TMD), and "others" groups. Within groups, patients were divided based on age and sex. Patients with abscess, the most frequent condition in the infection group, were divided according to the fascial area affected. The bleeding group was classified according to the cause of bleeding and the use of anticoagulant treatment. The TMD group was classified according to the etiology of the condition, while the "others" group included patients with neuropathic pain and prosthetic or orthodontic appliance dislocation. The percentages were calculated using the IBM SPSS Statistics 23.0 (IBM Corp., Armonk, NY, USA) program, and duplicate cases were analyzed for two or more disease groups.

\section{RESULTS}

\section{Total patients}

\section{Yearly distribution and sex distribution}

The number of patients annually visiting the emergency room increased from 2013 to 2016, although the average patient sex ratio (male:female) for each year remained constant at 1.98:1 (Fig. 1).

\section{Monthly distribution}

The monthly distribution of patients across years was $11.0 \%$ in May, $9.7 \%$ in June, and $9.1 \%$ in July, followed by $6.7 \%$ in February and 6.8\% in January. The trauma group accounted for the greatest proportion of patients visiting the emergency room, and the monthly distribution of trauma patients was highest in November $(80.0 \%)$ and May (78.4\%) and lowest in February (65.9\%) (Fig. 2).

\section{Age distribution}

When comparing the number of patients by age, most patients were under 10 years old $(n=1,331)$, while those over 70 years old was the least.

Soft tissue injuries occurred in $63.6 \%$ of patients below

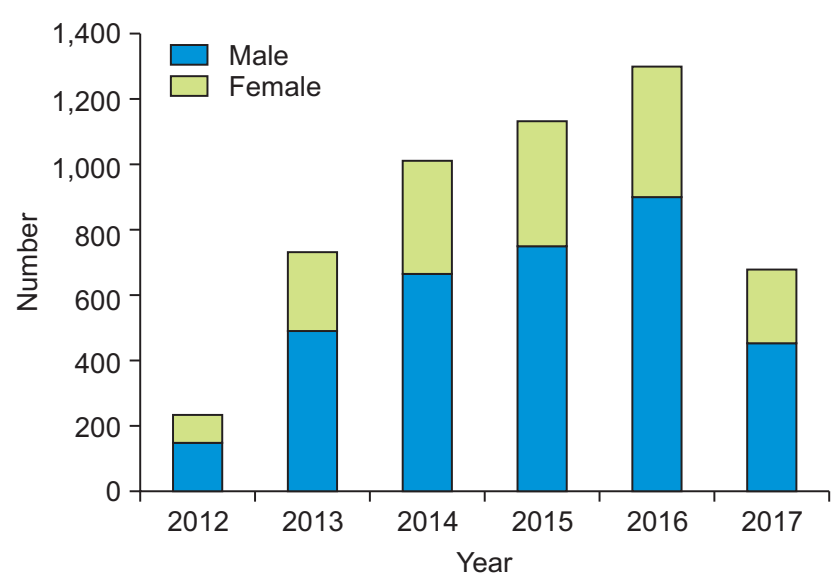

Fig. 1. Sex distribution of patients referred to the Department of Oral and Maxillofacial Surgery for treatment by year. 


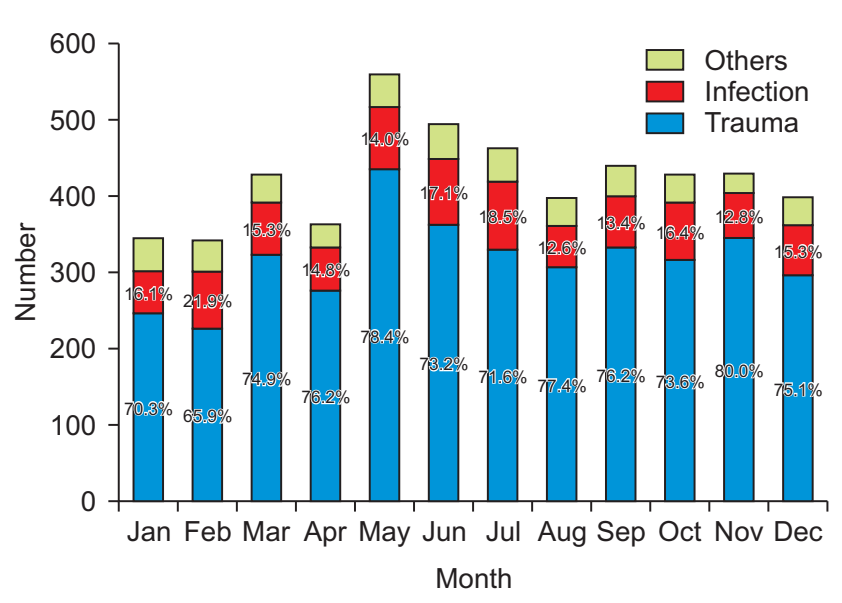

Fig. 2. Monthly distribution of emergency room patients referred to the Department of Oral and Maxillofacial Surgery for treatment.

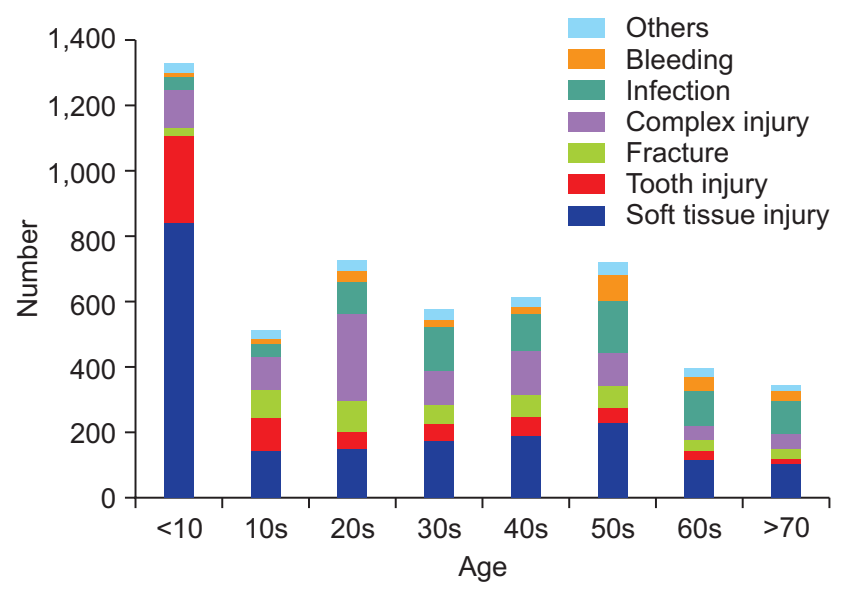

Fig. 3. Age distribution of emergency room patients referred to the Department of Oral and Maxillofacial Surgery for treatment.

10 years of age, and complex injuries were most frequent $(46.8 \%)$ in patients in their 20s. The percentage of infected and bleeding patients increased with age (Fig. 3).

\section{Etiology distribution}

The most common cause of injury in patients overall was slip down (49.2\%), followed by collision (16.8\%).

According to the monthly distribution, the sports trauma averaged $8.0 \%, 2.4 \%, 9.8 \%$, and $1.3 \%$ in June, July, September, and December, respectively (Fig. 4).

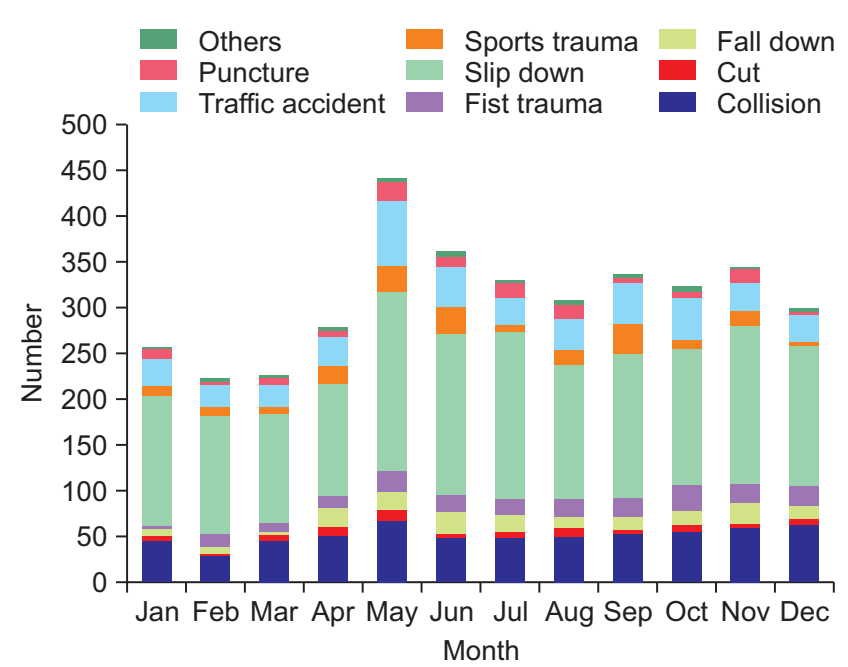

Fig. 4. Distribution of etiology of conditions in patients referred to the Department of Oral and Maxillofacial Surgery for treatment.

\section{Trauma group}

\section{Age distribution}

In the trauma group, $32.7 \%$ of patients were below 10 years of age, $11.9 \%$ were in their 40 s, and $11.7 \%$ were in their 50s.

\section{Trauma-type distribution}

Among 3,821 trauma patients, only $12.6 \%$ had fractures; $51.7 \%$ had lacerations, and $15.8 \%$ had tooth injuries. Among patients into two or more trauma categories, most had lacerations and tooth injuries (9.7\%), while few had a combination of fractures and tooth injuries (1.3\%).

\section{Etiology distribution}

Of the total 3,821 patients in the trauma group, $48.8 \%$ experienced trauma due to slip down, $16.9 \%$ were involved in collisions, and $11.8 \%$ were involved in traffic accidents (Table 1).

\section{Fracture group}

\section{Fracture site distribution}

The site with the highest frequency of fracture sites was the mandible (29.8\%), followed by the nasal bone $(27.0 \%)$. When the distribution of fractures of the mandible was examined, 117 cases $(33.2 \%)$ had a fracture of the condyle, 
Table 1. Comparative analysis of characteristics of patients in the trauma group $(\mathrm{N}=3,821)$

\begin{tabular}{|c|c|}
\hline Characteristic & Data \\
\hline \multicolumn{2}{|l|}{ Age (y) } \\
\hline$<10$ & $1,250(32.7)$ \\
\hline $10-19$ & $436(11.4)$ \\
\hline $20-29$ & $414(10.8)$ \\
\hline $30-39$ & $397(10.4)$ \\
\hline $40-49$ & $454(11.9)$ \\
\hline $50-59$ & $448(11.7)$ \\
\hline $60-69$ & $226(5.9)$ \\
\hline $70-79$ & $140(3.7)$ \\
\hline $80-89$ & $54(1.4)$ \\
\hline$\geq 90$ & $2(0.1)$ \\
\hline \multicolumn{2}{|l|}{ Trauma type } \\
\hline Fracture & $482(12.6)$ \\
\hline Laceration & $1,976(51.7)$ \\
\hline Tooth injury & $602(15.8)$ \\
\hline Fracture+laceration & $235(6.2)$ \\
\hline Fracture+tooth injury & $49(1.3)$ \\
\hline Laceration+tooth injury & $371(9.7)$ \\
\hline Fracture+laceration+tooth injury & $102(2.7)$ \\
\hline Fracture+infection & $4(0.1)$ \\
\hline \multicolumn{2}{|l|}{ Trauma cause } \\
\hline Collision & $647(16.9)$ \\
\hline Cut & $473(12.4)$ \\
\hline Fall down & $177(4.6)$ \\
\hline Fist trauma & $223(5.8)$ \\
\hline Slip down & $1,864(48.8)$ \\
\hline Sports trauma & $192(5.0)$ \\
\hline Traffic accident & $452(11.8)$ \\
\hline Puncture & $120(3.1)$ \\
\hline Others & $73(1.9)$ \\
\hline
\end{tabular}

Values are presented as number (\%).

followed by 71 cases $(20.2 \%)$ with a fracture around the symphysis. Fractures of the ramus occurred in 13 patients $(3.7 \%)$.

Of the 872 patients with fracture, only 507 cases (58.1\%) had single fractures, 320 cases $(36.8 \%)$ had double fractures, and 45 cases had more than 3 fractures.

\section{Etiology distribution}

The most common cause of fracture was slip down (38.6\%), followed by traffic accidents (19.2\%) (Table 2).
Table 2. Comparative analysis of characteristics of patients in the fracture group ( $\mathrm{N}=872)$

\begin{tabular}{lc}
\hline \multicolumn{1}{c}{ Characteristic } & Data \\
\hline Fracture site & \\
Orbital bone & $147(12.4)$ \\
Nasal bone & $320(27.0)$ \\
Naso-orbito-ethmoid complex & $7(0.6)$ \\
Zygomatico-maxillary complex & $182(15.4)$ \\
Maxilla & $98(8.3)$ \\
Alveolus & $77(6.5)$ \\
Mandible & $352(29.8)$ \\
Angle & $64(18.2)$ \\
Ramus & $13(3.7)$ \\
Body & $40(11.4)$ \\
Parasymphysis & $71(20.2)$ \\
Symphysis & $47(13.4)$ \\
Condyle & $117(33.2)$ \\
Fracture cause & \\
Collision & $110(12.6)$ \\
Fall down & $58(6.7)$ \\
Fist trauma & $113(13.0)$ \\
Slip down & $337(38.6)$ \\
Sports trauma & $70(8.0)$ \\
Traffic accident & $167(19.2)$ \\
Others & $17(1.9)$ \\
\hline
\end{tabular}

Values are presented as number (\%).

\section{Laceration group}

\section{Laceration site distribution}

The lip was the most frequent site of laceration (34.2\%), followed by the eyelid and eyebrow at $11.2 \%$, and the chin at $9.9 \%$.

\section{Etiology distribution}

The most common causes of lacerations were slip down (49.3\%), collision (17.7\%), and traffic accidents (12.4\%) (Table 3).

\section{Tooth injury group}

\section{Tooth injury-type distribution}

The most frequent tooth injury was tooth fracture (32.0\%), followed by avulsion (28.0\%), and subluxation (26.3\%).

\section{Etiology distribution}

Slip down was the most common cause of injury (53.3\%), 
Table 3. Comparative analysis of characteristics of patients in the laceration group $(\mathrm{N}=2,684)$

\begin{tabular}{lc}
\hline \multicolumn{1}{c}{ Characteristic } & Data \\
\hline Laceration site & $272(9.2)$ \\
Forehead & $332(11.2)$ \\
Eyelid, Eyebrow & $42(1.4)$ \\
Ear & $89(3.0)$ \\
Nose & $137(4.6)$ \\
Cheek & $1,012(34.2)$ \\
Lip & $89(3.0)$ \\
Frenum & $68(2.3)$ \\
Palate & $47(1.6)$ \\
Vestibule & $281(9.5)$ \\
Gingiva & $209(7.1)$ \\
Tongue & $45(1.5)$ \\
Buccal mucosa & $8(0.3)$ \\
Floor of mouth & $293(9.9)$ \\
Chin & $38(1.3)$ \\
Others & \\
Laceration cause & $474(17.7)$ \\
Collision & $78(2.9)$ \\
Cut & $142(5.3)$ \\
Fall down & $94(3.5)$ \\
Fist trauma & $1,322(49.3)$ \\
Slip down & $96(3.6)$ \\
Sports trauma & $332(12.4)$ \\
Traffic accident & $122(4.5)$ \\
Puncture & $24(0.9)$ \\
Others &
\end{tabular}

Values are presented as number (\%).

followed by collision (15.5\%) and traffic accident (11.3\%) (Table 4).

\section{Infection group}

A total of 768 patients visited the emergency room with infection; abscess accounted for $78.9 \%$ (606 patients) and other types of infection accounted for 21.1\% (162 patients).

\section{Abscess group}

\section{Site distribution}

Among patients with abscess, abscesses occurred most frequently in the vestibule $(39.7 \%)$, with the second-most frequent site of occurrence in the submandibular space (23.6\%), and the lowest frequency in the infratemporal space $(0.7 \%)$.
Table 4. Comparative analysis of characteristics of patients in the tooth injury group $(\mathrm{N}=1,124)$

\begin{tabular}{lc}
\hline Characteristic & Data \\
\hline Tooth injury cause & \\
Collision & $174(15.5)$ \\
Fall down & $38(3.4)$ \\
Fist trauma & $73(6.5)$ \\
Slip down & $599(53.3)$ \\
Sports trauma & $67(6.0)$ \\
Traffic accident & $127(11.3)$ \\
Others & $46(4.1)$ \\
Tooth injury type & \\
Avulsion & $391(28.0)$ \\
Intrusion & $53(3.8)$ \\
Extrusion & $30(2.1)$ \\
Subluxation & $368(26.3)$ \\
Tooth fracture & $448(32.0)$ \\
Concussion & $108(7.7)$
\end{tabular}

Values are presented as number (\%).

\section{Treatment}

Of the 606 patients with abscess, 141 underwent extraoral incision and drainage (I\&D), 356 received intraoral I\&D, 21 underwent only tooth extraction without I\&D, 71 received medication and injection, 15 referred to other departments, and 2 were treated with curettage.

Of the 141 patients who underwent extraoral I\&D, 111 (78.7\%) were admitted to the hospital, 19 were received outpatient treatment, 4 were referred to other hospitals, and 7 were not followed up. Of the 465 patients who underwent other treatments, 61 were hospitalized, 283 received outpatient treatment, 8 were referred to other hospitals, and 113 received no follow-up.

\section{Other infection group}

Cellulitis was the most frequent cause (39.5\%) of infection among the 162 patients in the other infections group, followed by 31 patients (19.1\%) with others.

Other groups included postoperative infection, maxillary sinusitis, and infected cystic lesions (Table 5). 


\section{Bleeding group}

\section{Causes of bleeding}

Of the 260 patients who visited the emergency room for bleeding, 205 (78.8\%) had bleeding after dental treatments, such as extraction, implantation, periodontal treatment, and other prosthetic restorations.

The most common causes of bleeding were extraction (50.0\%) and implantation (14.2\%). Other factors included irritation due to foreign bodies in the oral cavity, and other treatments, such as apitherapy.

Table 5. Comparative analysis of characteristics of patients in the infection group $(\mathrm{N}=768)$

\begin{tabular}{lc}
\hline \multicolumn{1}{c}{ Infection type } & Data \\
\hline Abscess & \\
Vestibular space & $269(39.7)$ \\
Canine space & $52(7.7)$ \\
Buccal space & $58(8.6)$ \\
Infratemporal space & $5(0.7)$ \\
Submental space & $29(4.3)$ \\
Sublingual space & $23(3.4)$ \\
Submandibular space & $160(23.6)$ \\
Submasseteric space & $36(5.3)$ \\
Pterygomandibular space & $21(3.1)$ \\
Temporal space & $6(0.9)$ \\
Deep neck infection & $19(2.8)$ \\
Other infection & \\
Cellulitis & $64(39.5)$ \\
Pericoronitis & $17(10.5)$ \\
Periodontitis & $20(12.3)$ \\
Sialadenitis & $19(11.7)$ \\
Osteomyelitis & $7(4.3)$ \\
Emphysema & $4(2.5)$ \\
Others & $31(19.1)$ \\
\end{tabular}

Values are presented as number (\%).

\section{Taking anticoagulant}

Of the total 260 patients, 68 patients (26.2\%) were taking anticoagulants, 169 (65.0\%) did not take the medication, and 23 patients (8.8\%) were unaware of this fact (Table 6).

\section{Temporomandibular joint disorders group}

Among 31 patients with TMD, temporomandibular joint (TMJ) dislocation occurred in 12 patients (38.7\%), masticatory myopathy syndrome in 17 (54.8\%), and internal derangement of the TMJ in 2 (6.5\%).

Of 12 patients with dislocation, $6(50.0 \%)$ had habitual dislocations while the other 6 had dislocations due to sudden opening or trauma. All patients were treated with closed reduction.

Patients with myofascial pain syndrome reported that the symptoms occurred after traffic accidents, fist trauma, or dental treatment, and were treated with medication.

\section{“Others” group}

Patients in the "others" group visited the emergency room with pulpitis, neuropathic pain, loss of orthodontic appliances or prostheses, and postoperative pain and edema.

\section{DISCUSSION}

This study reported that the overall sex ratio of patients treated in the department of OMS during the study period was 1.98:1 (male:female). On the other hand, Jang et al. [5] reported this ratio as 1.9:1, Baik et al. [10] as 1.72:1, and Kim et al. [11] as 1.73:1. It was not significantly different from the previous studies. In terms of age distribution

Table 6. Comparative analysis of characteristics in bleeding group $(\mathrm{N}=260)$

\begin{tabular}{lcccc}
\hline Cause of bleeding & Taking coagulant & Not taking coagulant & Unknown & Data \\
\hline Extraction & 28 & 95 & 0 & $130(50.0)$ \\
Implantation & 9 & 28 & 1 & $37(14.2)$ \\
Spontaneous bleeding & 13 & 18 & 0 & $32(12.3)$ \\
Periodontal treatment & 11 & 13 & 1 & $24(9.2)$ \\
Other dental treatment & 3 & 10 & 14 & $14(5.4)$ \\
Others & 4 & 5 & $23(8.8)$ \\
\hline
\end{tabular}


of these patients, most of the patients visiting the emergency room and requiring treatment at the department of OMS were younger than 10 years (26.1\%), followed by those in their 50s (14.2\%) and those in their 20s (12.1\%). As compared to other studies, Jang et al. [5] reported the age distribution frequency to be in the order of below 10 years, 20s, and then 40s, while Baik et al. [10] reported this frequency order to be below 9 years, 20s, and then 30s. Unlike other reports, the high percentage of individuals in their 40s and 50s may be because many individuals in their 20s and 30s had left the geographical region due to the recent loss of industrial growth in the Busan and Gyeongnam regions. In general, the higher percentage of injury among individuals under 10 years of age could be attributed to the higher likelihood of home injuries and the increased interest of parents in their children's oral health, which could lead to emergency rooms visit even in the case of minor injury.

In this study, trauma, infection, and intraoral bleeding were the most common reasons for visiting the emergency room. In trauma group, the laceration was the most frequent cause and the tooth injury was the second highest cause. Jang et al. [5] reported the frequency of injury in the order of soft tissue damage, tooth trauma, acute toothache, infection, intraoral bleeding, TMD, and facial bone fracture, while Baik et al. [10] reported an order of trauma, dental infection, infection, and oral bleeding (highest to lowest, in both cases).

Most previous studies have shown that trauma is the most frequent cause of visits to the emergency room [7,12], the present study additionally found that the frequency of multiple trauma was also high. In the case of complex trauma, prior preparation is required so that appropriate diagnosis and priority treatment can be provided [8].

The major causes of fracture were seen in the order of slip down, traffic accidents, and fall down; Yoon [13], Moon et al. [14], and Baik et al. [10] previously reported that fall down was the main cause of fracture. In this study, the order of frequency of factures were mandible, nasal bone, zygomatic bone, and blow out fractures. Nakamura and Gross [15] reported that the frequency of fractures was in the order of zygomatic bone, nasal bone, and mandible. Motamedi [8] stated the order to be mandible, zygomatic bone, and maxilla; whereas Jang et al. [5] reported an order of mandible, maxilla, and nasal bone. This difference seems to have been influenced by differences in the range of care provided at each hospital. Especially, compared with the study of Kim et al. [11], which was carried out before the transfer of dental clinic from Pusan to Yangsan, it can be confirmed that the incidence of nasal bone fracture patients is increased. This is because, as mentioned in Kim et al. [16], there is a shortage of plastic surgery emergency room that can be visited in case of fracture of nasal bone in Gyeongsangnam-do province, so many came to this department.

In the laceration group, the most frequent cause was slip down, as also reported by Jang et al. [5] Soft tissue damage frequently occurred in the order of lips, eyelids, eyebrows, and chin. Park et al. [17] stated that lip is easily damaged due to the protruding structure close to the hard tissue (i.e., teeth) and the damage can be easily recognized. Also, both eyebrows and chin are protruding parts, which easily lead to laceration, which is not different from previous studies.

In the tooth injury group, tooth fracture, avulsion, and tooth subluxation exhibited frequencies in a decreasing order of magnitude, and were mainly due to slip down and collisions. Only $15.8 \%$ of the total trauma group were injured only in the teeth. A total of $1.3 \%$ of cases were accompanied by fracture, $9.7 \%$ of cases were accompanied by laceration, and $2.7 \%$ of teeth with fracture and laceration. This seems to be due to visiting a local dental clinic on the day of the injury or the next day rather than looking for an emergency room in the event of tooth-only injury.

In the infection group, abscess was the most frequent cause (78.9\%). Kim et al. [12] reported a higher incidence of buccal space abscess followed by submandibular space abscess, while Jang et al. [5] reported an order of submandibular space abscess, buccal space abscess, and canine clearance abscess. Most patients with abscess were treated by I\&D or tooth extraction. The incidence of complications, such as acute airway obstruction, was very high in cases of deep neck infections. Therefore, most of these cases were treated after consultation with other departments. Patients with other infectious diseases were referred to our clinic when they had complications of cellulitis, secondary infection, or maxillary sinusitis. 
In the bleeding group, $78.8 \%$ of patients visited the emergency room due to bleeding that persisted after dental treatments, such as extraction, implantation, and periodontal treatment, but only $26.2 \%$ of them were taking anticoagulants. Dental treatment is the main cause of intraoral bleeding and few patients presenting medical factors, such as being under anticoagulant therapy. It is important to record full history of the patient before dental treatment and have thorough knowledge of procedures such as hemostasis and exercising post-operative caution.

Of 12 patients with TMD, 50\% had habitual dislocation. All patients were treated with closed reduction. Masticatory myofascial pain syndrome occurred after traffic accident, injury, and recent dental treatment, in patients without pre-existing TMD. In this study, the number of patients who visited our clinic for TMD was very low compared to those in other hospital reports. This may be because the emergency medical department only refers patients to the oral-maxillofacial surgeon if additional evaluation and treatment is needed after pre-treatment. Other patients included patients with dental pain, neuropathic pain, loss of intraoral devices such as orthodontic appliances and prostheses, and postoperative pain and edema.

In conclusion, there was no significant difference in the type and frequency of injuries and the cause of injuries among the patients visiting the emergency room and treated at the department of oral maxillofacial region in comparison with previous studies in various regions. Also, there was no significant difference when comparing with previous study conducted before the transfer of dental hospital from Pusan to Yangsan. However, the causes of emergency room visits, such as infection, hemorrhage, and TMD, vary widely and are complicated. Thus, it is necessary to acquire thorough knowledge in dentistry to perform accurate diagnosis and provide appropriate treatment, and to cooperate closely with other dental departments, such as pediatric dentistry, conservative dentistry, and oral medicine.

\section{ACKNOWLEDGEMENTS}

This research supported by 2 year research grant of $\mathrm{Pu}-$ san National University (2016).

\section{CONFLICTS OF INTEREST}

The authors declare that they have no competing interests.

\section{ORCID}

\author{
Si-Yeon Park \\ https://orcid.org/0000-0001-6643-3907 \\ Jae-Min Song \\ https://orcid.org/0000-0002-4047-2163 \\ Jun-Ho Lee \\ https://orcid.org/0000-0001-6027-102X \\ Jae-Yeol Lee \\ https://orcid.org/0000-0003-0678-2499 \\ Dae-Seok Hwang \\ https://orcid.org/0000-0001-6899-1769 \\ Yong-Deok Kim \\ https://orcid.org/0000-0002-5807-7487 \\ Sang-Hun Shin \\ https://orcid.org/0000-0002-0467-6206 \\ Uk-Kyu Kim \\ https://orcid.org/0000-0003-1251-7843
}

\section{REFERENCES}

1. Huelke DF, Compton CP. Facial injuries in automobile crashes. J Oral Maxillofac Surg 1983;41:241-244. doi: 10.1016/0278-2391(83)90266-5.

2. Schultz RC. Facial injuries. 2nd ed. Chicago: Year Book Medical Publishers; 1977.

3. Topazian RG, Gldberg MH. Management of infections of the oral and maxillofacial regions. Philadelphia: W.B. Saunders; 1981.

4. Roitt IM, Lehner T. Immunology of oral diseases. 3rd ed. London: Blacwell Scientific Publications; 1992.

5. Jang CS, Lee CY, Kim JW, Kim JH, Kim JY, Kim YH, Yang BE. A clinical study on the dental emergency patients visiting an university hospital emergency room. J Korean Assoc Oral Maxillofac Surg 2011;37:439-447. doi: 10.5125/jkaoms.2011.37.6.439.

6. Lee SS, Kim SG, Oh JS, Moon SY, You JS, Yu KH, Jo JH, Park JS, Yang WS, Seo DK. Retrospective study on the flow and characteristics of dental emergency patients in Chosun University Hospital. J Korean Dent Sci 2015;8:10-15. doi: 10.5856/JKDS.2015.8.1.10.

7. Kim SJ, Kim WJ, Lee BJ. Cognition of 119 emergency medical technicians on dental emergency treatment in the Jeju 
province. J Korean Acad Oral Health 2012;36:131-136.

8. Motamedi MH. An assessment of maxillofacial fractures: a 5-year study of 237 patients. J Oral Maxillofac Surg 2003;61:61-64. doi: 10.1053/joms.2003.50049.

9. Keum KC, Paeng JY, Choi BY, Choi JG, Oh SR, Lee J, Choi MK, Kwon KH, Oh SH, Min SK. An clinical analysis on the dental emergency patients visiting the emergency room of Dental Hospital of Won-Kwang University. Maxillofac Plast Reconstr Surg 2009;31:35-40.

10. Baik JS, Yoon KH, Park KS, Cheong JK, Shin JM, Choi $\mathrm{MH}$, Kwon J. A clinical study on the emergency patients of oral and maxillofacial surgery visiting Sang-Gye Paik Hospital emergency room. Maxillofac Plast Reconstr Surg 2008;30:561-566.

11. Kim JR, Chung IK, Yang DK, Park BW. A clinical study on the emergency patients of oral and maxillofacial surgery during recent 5 years. Maxillofac Plast Reconstr Surg 2001;23:155-162.

12. Kim MS, Nam OH, Kim SG, Cho SI. A clinicostatistical analysis of oral and maxillofacial infected patient. Maxil- lofac Plast Reconstr Surg 2002;24:317-324.

13. Yoon OK. Clinico-roentgenographic studies on fracture lines of the maxillofacial bones. J Korean Assoc Oral Maxillofac Surg 1976;14:179-184.

14. Moon WK, Jung YS, Lee EW, Kwon HK, Yoo JH. The characteristics on the dental emergency patients of Wonju Christian Hospital for last 10 years. J Korean Assoc Oral Maxillofac Surg 2004;30:34-42.

15. Nakamura T, Gross CW. Facial fractures. Analysis of five years of experience. Arch Otolaryngol 1973;97:288-290. doi: 10.1001/archotol.1973.00780010296016.

16. Kim HG, Son YH, Chung IK. Facial bone fracture patients visiting Pusan National University Hospital in Busan and Yangsan: trends and risks. Maxillofac Plast Reconstr Surg 2014;36:140-145. doi: 10.14402/jkamprs.2014.36.4.140.

17. Park KH, Song JM, Hwang DS, Kim YD, Shin SH, Kim UK, Lee JY. A clinical study of emergency room visits for oral and maxillofacial lacerations. J Korean Assoc Oral Maxillofac Surg 2015;41:246-250. doi: 10.5125/jkaoms.2015.41.5.246. 